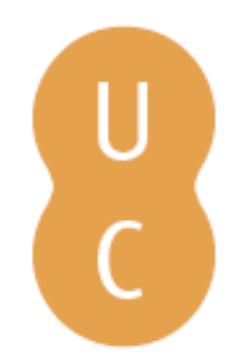

\title{
nommalina
}

\section{A determinação do valor das bibliotecas universitárias na Sociedade da Informação e do Conhecimento}

\author{
Autor(es): $\quad$ Marques, Maria Beatriz \\ Publicado por: Imprensa da Universidade de Coimbra \\ URL \\ persistente: URI:http://hdl.handle.net/10316.2/36981 \\ DOI: $\quad$ DOI:http://dx.doi.org/10.14195/978-989-26-1045-0_10 \\ Accessed : $\quad$ 26-Apr-2023 13:20:01
}

A navegação consulta e descarregamento dos títulos inseridos nas Bibliotecas Digitais UC Digitalis, UC Pombalina e UC Impactum, pressupõem a aceitação plena e sem reservas dos Termos e Condições de Uso destas Bibliotecas Digitais, disponíveis em https://digitalis.uc.pt/pt-pt/termos.

Conforme exposto nos referidos Termos e Condições de Uso, o descarregamento de títulos de acesso restrito requer uma licença válida de autorização devendo o utilizador aceder ao(s) documento(s) a partir de um endereço de IP da instituição detentora da supramencionada licença.

Ao utilizador é apenas permitido o descarregamento para uso pessoal, pelo que o emprego do(s) título(s) descarregado(s) para outro fim, designadamente comercial, carece de autorização do respetivo autor ou editor da obra.

Na medida em que todas as obras da UC Digitalis se encontram protegidas pelo Código do Direito de Autor e Direitos Conexos e demais legislação aplicável, toda a cópia, parcial ou total, deste documento, nos casos em que é legalmente admitida, deverá conter ou fazer-se acompanhar por este aviso.

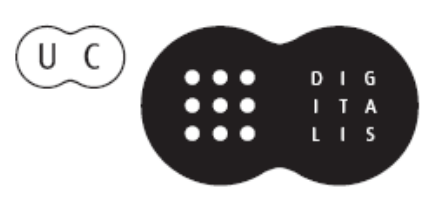



Tendo como pano de fundo as Comemorações dos seus 500 anos, a Biblioteca Geral da Universidade de Coimbra organizou um Congresso Internacional subordinado ao tema "A Biblioteca da Universidade: permanência e metamorfoses", que teve lugar nos dias 16, 17 e 18 de janeiro de 2014, no auditório da Reitoria da Universidade de Coimbra.

O objetivo maior desta reunião científica foi o de refletir sobre o presente e o futuro das bibliotecas que servem públicos universitários. Numa outra vertente, procurou chamar-se a atenção para a importância de que a Biblioteca se reveste, tendo em vista o progresso do conhecimento técnico e científico. Por último, o Congresso pretendeu instituir-se como oportunidade de reflexão prospetiva e como lugar de encontro entre as sensibilidades de todos os que trabalham profissionalmente com livros e com outros suportes de natureza bibliográfica.

Nesse sentido, foram apresentadas Conferências, Mesas Redondas e sessões de Testemunhos em torno de temas como o valor das bibliotecas universitárias, a biblioteca universitária em contexto; as mudanças e os desafios; a biblioteca universitária e a sociedade da informação e conhecimento; o impacto do acesso aberto na comunidade científica, e as bibliotecas digitais. 


\title{
MARIA BEATRIZ MARQUES
}

Universidade de Coimbra

University of Coimbra

\section{A DETERMINAÇÃO DO VALOR DAS BIBLIOTECAS UNIVERSITÁRIAS NA SOCIEDADE DA INFORMAÇÃO E D O CONHECIMENTO}

\author{
DETERMINING THE VALUE OF UNIVERSITY LIBRARIES \\ IN THE INFORMATION AND KNOWLEDGE SOCIETY
}

RESUMO: Partindo de uma análise da tradicional perspetiva que tem estado subjacente à operação de "avaliação do desempenho" dos Serviços de Informação, apresenta-se um novo modelo de abordagem que encara a determinação do valor das Bibliotecas Universitárias como uma operação de natureza estratégica no âmbito do seu Planeamento e Gestão pela Qualidade Total.

Como consequência do reconhecimento do elevado grau de complexidade e dificuldade sentida no cumprimento dos objetivos que lhes estão consignados na Sociedade da Informação e/ou do Conhecimento, defende-se a necessidade de uma nova visão das Bibliotecas Universitárias, que coloque os interesses dos clientes no centro da sua gestão.

Afirma-se que a prestação de serviços de informação de qualidade e o facultar o acesso à informação, já não é, per se, suficiente para satisfazer as necessidades da comunidade universitária no domínio da formação, do ensino e da investigação, mormente quando se pretende preparar cidadãos com competências, conhecimentos e resultados de aprendizagem que os valorizem individualmente como elementos cruciais para o desenvolvimento económico, social e cultural sustentável.

Conclui-se que a resposta aos desafios do novo milénio implica uma melhoria contínua das Bibliotecas Universitárias através de uma permanente medição do grau de satisfação dos seus clientes em relação aos serviços prestados e uma subsequente otimização dos seus recursos financeiros, estruturais e humanos.

Palavras-chave: Biblioteca Universitária, Planeamento estratégico, Gestão da qualidade total (GQT), Avaliação, Mediação, Satisfação de Clientes.

ABSTRACT: Based on an analysis of the traditional perspectives underlying the Information Services "performance assessment" exercise, a new model is presented for 
the approach to evaluating university libraries as a strategic operation within overall Planning and Total Quality Management.

Recognising the high level of complexity and difficulty experienced in fulfilling the objectives assigned by the Information and/or Knowledge Society, it is argued that there is a need for a new vision of university libraries which places the interests of clients at the centre of their management.

It is acknowledged that providing quality information services and facilitating access to information is no longer sufficient, per se, to meet the needs of the university community in terms of training, education and research, particularly when the aim is to prepare citizens with skills, knowledge and learning outcomes that empower them individually as vital elements of sustainable economic, social and cultural development.

It may be concluded that the response to the challenges of the new millennium involves ongoing improvements to university libraries by continuously measuring the level of client satisfaction with the services provided and the subsequent optimisation of their financial, structural and human resources.

Os organismos vivos encontram-se em constante modificação, assumindo uma sucessão de 'estados' definidos por padrões variados de actividades em curso em cada um dos seus componentes

ANTÓNIO R. DAMÁSIO - O erro de Descartes

\section{Introdução}

As Bibliotecas Universitárias (BU), enquanto organizações, são organismos vivos, que surgem para desempenhar uma função que é sentida como necessária para outros agentes do meio ambiente. Por isso, enquanto organização, só poderá existir se houver interessados nos produtos ou serviços por ela oferecidos.

Assim, a missão das BU é um constructo em evolução e tem de poder ser adaptada com flexibilidade a um meio ambiente em rápida e complexa mutação.

Apesar das suas funções de Recolha, Conservação e Difusão da Memória da Humanidade serem eternas, a sua missão vai adaptar-se às necessidades de uma Sociedade cada vez mais exigente em relação às organizações 
que cria e que, como é o caso da maioria das BU portuguesas, financia direta e indiretamente.

A Sociedade Digital, para além de conduzir ao fim do monopólio das bibliotecas como organizações formais de transferência da informação e, consequentemente, ao fim das vantagens que este proporcionava, exige organizações flexíveis com uma missão em permanente construção e dependente das alterações cíclicas do meio ambiente, cada vez mais desordenado e indisciplinado.

O acesso à informação deixa de constituir a prioridade da Sociedade do Conhecimento, impondo-se o seu processamento, a transformação do seu valor latente em valor real, a sabedoria, que conduza as organizações à aquisição da chamada inteligência competitiva.

É esta a razão que assegura a permanência da Biblioteca como o centro nevrálgico da universidade e que sustenta a sua missão no século XXI - transformar as crenças verdadeiras da humanidade em crenças verdadeiras e justificadas, ou seja, em conhecimento útil que conduza a um desenvolvimento sustentável da Universidade.

Assim, a personalidade de cada organização, a sua vantagem competitiva, é definida, e reconhecida, em função da sua capacidade de adaptação e reação a cada ciclo social, criando e inovando permanentemente, através de um processo contínuo de aprendizagem assente na condução racional das atividades dos seres humanos que as movimentam e em função da combinação possível entre o real e o imaginário, entre o bom e o ótimo.

Por isso, da mesma forma que não existem dois seres humanos iguais, também não existem duas BU iguais, pelo que o funcionamento de cada BU deverá ser determinado pelas exigências e condicionantes da envolvente interna e externa da organização em concreto.

\section{A Avaliação das Bibliotecas Universitárias no século XXI}

No contexto da Sociedade do Conhecimento, não podemos olhar para o valor das BU e para o valor da sua informação em abstrato, daí a necessidade de as contextualizar e de as analisar em correlação com o 
uso que cada indivíduo lhe confere ${ }^{1}$, com as suas prioridades em determinado momento e lugar ${ }^{2}$.

Os 500 anos que medeiam entre a primeira BU portuguesa (1513) e a atual BGUC assinalam uma evolução paradigmática do seu objeto de investigação - da conservação das coleções ao acesso à informação e do acesso à informação ao seu processamento, uso e transformação.

Independentemente da sua maior ou menor longevidade, da riqueza das suas coleções, dimensão física, etc., as BU têm de se reinventar, de inovar, de reconfigurar os seus recursos - Pessoas, Processos e Tecnologia - e de os gerir de uma forma integrada.

Assim, os recursos existentes, e independentemente da sua dimensão, deverão ser objeto de uma cultura de avaliação que contribua para a melhoria e para a afirmação das BU como equipamentos imprescindíveis para a medição do valor das universidades.

Nesta perspetiva é necessário que as BU acompanhem as mudanças permanentes que ocorrem no ensino superior, encarando-as como oportunidades para a melhoria do seu desempenho, e que adaptem os seus modelos de negócio às novas realidades das Universidades.

Todavia, e para que a avaliação possa funcionar como uma oportunidade estratégica para a Biblioteca criar valor para a Universidade, torna-se imprescindível o desenvolvimento de uma nova cultura organizacional e de uma nova visão da organização e da sua missão no novo milénio.

1 O valor da informação apenas pode ser considerado no contexto do seu uso, this means that the value of information can be determined post facto - after benefits have emerged from its use in some decision situation - but not before its use. The economics of information. In International Encyclopedia of Information and Library Science. London; New York: Routledge, 1997. ISBN 0-415-09860-2, p. 191. McGARRY, K. J. - Da documentação à informação: um contexto em evolução. Lisboa: Editorial Presença, 1984, p. 79, afirma que o cérebro humano tem a capacidade de percecionar, codificar, armazenar, recuperar $e$ manipular a informação, de acordo com as suas necessidades individuais.

2 DuvolD, Ellen-Merete - The meaning of the public library in people's everyday life: some preliminary results from a qualitative study. In JOHANNSEN, Carl Gustav; KAJBERG, Leif, ed. - New frontiers in public library research. Maryland: Scarecrow Press, 2005. ISBN 0-8108-5039-7, p. 274, assinala a necessidade de contextualizar a informação e sobretudo o conhecimento que ela pode gerar: information is something we consume, something that does not invite reflection...knowledge, however, is constructed and produced by people; it cannot be seen as isolated. 
Tal mudança implica a assunção de novas atitudes e a aquisição de novas competências, ou a reconstrução das antigas, por parte das diversas pessoas envolvidas na organização; novos métodos e novas práticas conducentes a uma agilização e concomitante simplificação dos processos; e, finalmente, mas não menos importante, a aquisição e o desenvolvimento de novas ferramentas tecnológicas, agora menos direcionadas para a ligação em rede das máquinas existentes, mas especialmente vocacionadas para a ligação das pessoas in e out da organização.

A questão central da discussão a desenvolver neste novo ambiente social gira em torno de um conceito, entendido como dinâmico e subjetivo - o conceito de valor.

Assim, torna-se urgente a determinação do que se entende por valor na Sociedade em $\operatorname{Rede}^{3}$.

Do ponto de vista da economia empresarial, o valor é um fator exógeno à organização, é o preço justo de determinado produto ou serviço, físico ou virtual, aferido em função do que os clientes estão dispostos a pagar e não em função dos custos de produção.

Uma análise diacrónica da evolução deste conceito permite-nos tirar conclusões sobre as diferentes perspetivas que estiveram em jogo no processo de avaliação das BU, as quais resultam das diversas necessidades das Universidades ao longo da sua longa história ${ }^{4}$.

De origem medieval ${ }^{5}$ - séculos XIII e XIV - as primeiras BU surgem com um valor essencialmente utilitário. O sucesso das Universidades estava associado diretamente à sua capacidade para fornecerem aos estudantes uma formação de natureza prática, que lhes permitisse ganhar a vida

3 Ver CASTElls, Manuel - A sociedade em rede - a era da informação: economia, sociedade e cultura. v. 1. São Paulo: Paz e Terra, 1999.

4 As Universidades surgem na Europa no século XII.

5 As bibliotecas universitárias mais famosas são a da UNIVERSIDADE DE PARIS - 1257, quando Roberto Sorbonne, capelão de Luis IX, criou uma instituição para os estudantes pobres de teologia, à qual entregou os seus livros. Em 1338, o catálogo da biblioteca apontava para a existência de 1.722 obras; a da UNIVERSIDADE DE OXFORD, criada por um grupo de estudantes ingleses da Universidade de Paris em 1327, quando Thomas Cobham, bispo de Worcester, legou à biblioteca universitária uma quantidade de dinheiro e os seus livros. No século XVI, com Eduardo VI, ela foi totalmente destruída, chegando-se mais tarde inclusive a vender os seus móveis, dado não albergarem nenhum volume. 
exercendo a medicina, assessorando em questões jurídicas, atuando como secretários ou simplesmente ao serviço da Igreja.

Este tipo de formação refletiu-se no conteúdo das BU, cujos livros se consideravam meros instrumentos para a transmissão dos conhecimentos e eram, por conseguinte, mais ferramentas de trabalho do que objetos dignos de veneração.

Assim, até à Sociedade Industrial ou custodial, o valor da BU residia na quantidade e qualidade dos documentos que conservava nas suas coleções.

Na Sociedade da Informação ou pós-custodial, o valor da BU residia na quantidade e qualidade do acesso à informação contida nos documentos que enriqueciam as suas coleções.

De uma sociedade massificada e hierárquica, que privilegiava a propriedade dos meios de produção e a conservação física dos bens e dos serviços produzidos $^{6}$, evoluiu-se para uma sociedade personalizada e horizontal, designada por Toffler como terceira onda ${ }^{7}$, que valorizava o acesso a esses meios, produtos e serviço $^{8}$, enquanto garantia de desenvolvimento e de bem-estar individual e coletivo.

A alteração das expetativas da sociedade da informação em relação às $\mathrm{BU}$, acentuada de uma forma significativa pelo aparecimento das novas tecnologias ${ }^{9}$, provoca uma desagregação da sua cadeia de valor e despoleta a necessidade de repensar o seu modelo de negócio ${ }^{10}$.. reciclando os modelos existentes, na sua grande maioria controlados pelos fornecedores

6 Como refere RIFKIN, Jeremy - A era do acesso: a revolução da nova economia. Lisboa. Editorial Presença, 2001. ISBN 972-23-2741-0, p. 18, na sociedade moderna ou industrial, a ideia de propriedade baseia-se no valor atribuído à posse de um património material ou fundiário por uma duração mais ou menos determinada. "Ter", "possuir"," acumular" foram sempre valores muito apreciados.

7 Comummente designada por Sociedade pós-moderna ou Sociedade da Informação. A designação utilizada por Alvin Toffler - third wave serviu, em 1981, para caraterizar, prospetivamente, a nova ordem económica do século XXI. A primeira onda foi a agrícola e a segunda foi a industrial. Ver TOFFLER, Alvin - The third wave. New York: Bantan Books, 1981. ISBN 0-553-22635-5.

8 Como refere RIFKIN, Jeremy - A era do acesso: a revolução da nova economia, p. 16, esta nova sociedade, ou era, vê as redes tomarem o lugar dos mercados e a noção de acesso substituir-se à de propriedade.

9 Particularmente da de WEB, que veio consagrar a distribuição massiva de informação, permitindo a convergência da informação - texto, som, imagem e vídeo.

10 A razão de ser da sua existência, crescimento e manutenção. 
de informação - Arquivistas e Bibliotecários - na direção dos clientes, $e$ justificando o aperfeiçoamento e/a personalização dos produtos e serviços em função dos seus perfis ${ }^{11}$, não das normas em vigor e muito menos dos clientelismos ou interesses individuais e/ou corporativos ${ }^{12}$.

$\mathrm{Na}$ atual Sociedade do Conhecimento ou pós-moderna, o valor da BU reside na sua capacidade de produzir conhecimento, assistindo-se a um redirecionamento do conceito de valor do capital material ${ }^{13}$ para o capital intelectual ${ }^{14}$, o qual tem no conhecimento ${ }^{15}$ o seu recurso mais valioso e na informação ${ }^{16}$ a sua fonte de energia.

11 Galvão, Maria Cristiane Barbosa - Construção de conceitos no campo da Ciência da Informação. Ciência da Informação. Vol. 27, $\mathrm{n}^{\circ} 1$ (1998), p. 49, afirma que os produtos e serviços oferecidos pela biblioteconomia e documentação não são neutros. Eles moldam as necessidades dos usuários dos sistemas de informação, em função dos pressupostos e das necessidades internas dos sistemas. Daí a necessária passagem dos sistemas normativos, dos modelos estáticos, para os modelos flexíveis, e isto porque o objeto das ciências humanas (o ser bumano) sofre alterações com o passar do tempo. Entendendo que o usuário da informação é um ser bumano, a biblioteconomia e documentação teriam seus objetivos centrados não apenas na otimização dos serviços que prestam à sociedade, estariam atentas às mudanças, às novas exigências informacionais, e proporiam serviços e conceitos compatíveis com os diferentes momentos bistóricos.

12 MARQues, Maria Beatriz Pinto de Sá Moscoso - Utilizadores ou Clientes? Inovação na Visão dos Serviços de Informação no Século XXI. In SEMINÁRIOS DE SABERES ARQUIVÍSTICOS (SESA): reflexões e diálogos para formação do arquivista. Curitiba: Appris, 2013, vol.1, p. 181-204. ISBN 978-85-8192-225-6, p. 215.

13 Para os iluministas, como John Locke, David Hume, Adam Smith, etc., a criação de propriedade também era apanágio do ser humano, que através do seu trabalho sobre o material em bruto que a natureza lhe disponibilizava, produzia objetos de valor acrescentado, os quais trocava entre si.

14 Passa a ser o motor da criatividade e da inovação e, porquanto, o principal ativo dos indivíduos, das organizações e dos países, em oposição ao capital material, que transita para o domínio dos seus passivos. Tal como afirmou o visionário DRUCKER, Peter F. Post-Capitalist Society. New York: Harper Collins, 1993, p. 183, No passado, as fontes de vantagem competitiva eram o trabalbo e os recursos naturais, agora e no próximo século, a chave para construir a riqueza das nações é o conbecimento.

15 O conhecimento é uma capacidade cognitiva, exclusiva do ser humano e não pode ser considerado propriedade de ninguém. O conhecimento obtém-se a partir do processamento dos dados e da informação e na sua transformação em ações. A transmissão do conhecimento é possibilitada pelos processos intelectuais de ensino e de aprendizagem. Como afirmam MATOS, Florinda; LOPES, Albino - Gestão do capital intelectual: a nova vantagem competitiva das organizações. Comportamento Organizacional e Gestão [Em linha]. Vol. 14, $\mathrm{n}^{\circ} 2$ (2008), p. 234. [Consult. 2013-04-28]. Disponível em www: <URL: http://www.scielo.oces.mctes.pt/ pdf/cog/v14n2/v14n2a07.pdf, o conbecimento é a informação que ao ser usada pela mente bumana permite a tomada de decisão em determinado contexto.

16 Entendida como um conjunto de dados estruturados e formatados, disponível em vários formatos, que pode ser acumulada pelo ser humano, ao qual é externa, mas que pode ser utilizada para gerar conhecimento. A informação usada, só é útil quando é relevante, 
Neste sentido, a relação que se estabelece na Sociedade em Rede entre informação e conhecimento é cada vez menos linear.

A informação é concetualizada como a matéria-prima de que deriva o conhecimento - fonte inesgotável de riqueza -, mas não basta ser o seu proprietário, é preciso ser o seu usufrutuário, é preciso acrescentar-lhe valor, é preciso compreendê-la, interpretá-la e utilizá-la como a vantagem competitiva das BU para o desenvolvimento da missão da Universidade - o ensino, a investigação e a aprendizagem.

Daqui decorrem várias interrogações. Qual é o preço justo das BU? Qual é a importância das BU? Qual é o custo das BU e quais são os benefícios advindos da sua existência? Qual é o sentido, a significação, a interpretação, a estimativa em relação às $\mathrm{BU}$ ?

Esta abordagem das BU como agentes criadores de valor insere-se no âmbito da chamada Nova Gestão Pública ${ }^{17}$, assente em evidências e não em pressupostos, onde o valor das organizações em geral passa a ser determinado pelo seu uso, pelos benefícios que delas podem advir para o bem-estar social.

Esta evidência, que esteve na base da evolução do estudo do documento, do contentor, para o estudo da informação, do conteúdo, tem efeitos diretos na avaliação das BU no século XXI, na fixação do seu valor institucional e social, o qual deixa de ser determinado pela tecnologia e passa a ser determinado pelas pessoas - mediadores ${ }^{18}$ e mediados -, as únicas capazes de criar, de inovar e dessa forma acrescentar valor às organizações, aumentando a sua qualidade, competitividade e produtividade.

A Sociedade em Rede implica uma mudança paradigmática do estudo dos meios para o estudo epistemológico das pessoas - dos proprietários

ou seja, quando gera conhecimento, quando contribui para a tomada de decisões que promovem o desenvolvimento do ser humano.

17 O chamado New Public Management ou Nova Gestão Pública, uma ideologia neoliberal, onde domina uma fraca intervenção do estado a nível económico e cultural, que se veio sobrepor ao modelo de Estado Providência, (Welfare State, que se tinha começado a implantar na Europa depois da $2 .^{a}$ guerra mundial e que associado à noção de cidadania consagrava uma série de direitos sociais), impondo o papel do mercado como o modelo ideal.

18 Do latim mediatiore, que significa aquele, ou aquilo, que medeia ou intervém, o intermediário, ato ou efeito de mediar, intermediação. 
e dos deserdados, dos conectados e dos desconectados ${ }^{19}$, dos incluídos e dos excluídos ${ }^{20}$-, dos seus valores, das suas necessidades, das suas expectativas, as quais determinam o uso do conteúdo dos contentores, ou seja, como os seres humanos pensam, agem, sentem e geralmente tratam os problemas do dia- $a$ - dia ${ }^{21}$.

Assim, quando falamos em determinação do valor económico e social das $\mathrm{BU}$, estamos a referirmo-nos à riqueza, à importância, ao sentido, ao significado, à sua utilidade para a condução racional das atividades dos seres humanos, la posibilidad práctica de aplicar un conocimiento a una demanda concreta ${ }^{22}$ e, em simultâneo, à proporção entre uma quantidade que se dá, no caso das $\mathrm{BU}$, maioritariamente por uma via indireta - através dos impostos dos cidadãos -, e por uma via direta - as propinas pagas pelos estudantes, e outra que se recebe em troca, o conhecimento gerado que possibilita a criatividade e a inovação.

Ora, o facto de o conhecimento ser intangível e de as diversas tentativas para o definirem resultarem por lo general a un labirinto del que no hay una salida airosa ${ }^{23}$, faz com que a sua demonstração seja extraordinariamente difícil, senão mesmo impossível ${ }^{24}$, sobretudo se pretendermos traduzir, ou mensurar, os benefícios ou o valor económico da informação e dos Serviços de Informação ${ }^{25}$.

19 RIFKIN, Jeremy - A era do acesso: a revolução da nova economia, p.27.

20 Idem, ibidem, p. 216.

21 McGARRY, K. J. - Da documentação à informação: um contexto em evolução, p. 37.

22 CAPURRO, R. - Epistemología y ciencia de la información. Acimed: revista cubana de los profesionales de la información y la comunicación en salud. Vol. 21, n. ${ }^{\circ} 2$ (2010), p. 257.

23 TOFFleR, Alvin; TOFFlER Heidi - La revolución de la riqueza. Barcelona: Debate, 2006. ISBN 84-8306-674-2,p. 153.

24 Mormente se tivermos em linha de conta a dificuldade em conhecer os comportamentos e as atitudes do objeto de estudo - o ser humano - enquanto complexo bio-psico-sociocultural. Ver MORIN, Edgar - O paradigma perdido: a natureza bumana. 3. ${ }^{\mathrm{a}} \mathrm{ed}$. Mem Martins: Europa América, 1975.

25 Sobre este assunto consultar as obras LANCASTER, Frederick Wilfrid - If you want to evaluate your library. 2nd ed. London: Library Association Publishing, 1993. ISBN 1-85604-083-6; The measurement and evaluation of library services. Washington: Information Resources, 1977. ISBN 087815017X; Principes directeurs pour l'évaluation des systèmes et services d'information. Paris: Unesco, 1978. 180 p. (Unesco; PGI-78/WS/18). 
Esta dificuldade, ou impossibilidade, suscitada pela natureza intrínseca da riqueza desta nova sociedade ${ }^{26}$, pode ser colmatada, pelo menos a longo prazo, pela exigência e obrigatoriedade de conhecer os atalbos para a mente bumana - os valores, as necessidades, as atitudes e os comportamentos que regem a chamada aldeia global, a informação pessoal - a propriedade do século XXI - nas suas esferas pública e, sobretudo, privada 27 .

\section{O valor económico e social das Bibliotecas Universitárias no con- texto da Sociedade do Conhecimento: a mediação da informação}

Enquanto partes integrantes da estratégia das Universidades ${ }^{28}$, as BU sempre assumiram como valor principal, quer implícita quer explicitamente $^{29}$, a função de mediação da informação ${ }^{30}$, entendida como toda la acción de interferencia - realizada por el profesional de la información - directa o indirecta; conciente o inconsciente; individual o colectiva; que propicia la apropiación de la información que atienda, plena o parcialmente, una necesidad informacional ${ }^{31}$ dos utilizadores.

Todavia, a complexidade desta função da BU na Sociedade Digital, para além de lhe conferir um estatuto privilegiado para o êxito das polí-

26 Toffler, Alvin; TOFFler, Heidi - The third wave, p. 154-156, desenvolvem 10 caraterísticas do conhecimento que o distinguem de todas as outras fontes de riqueza.

27 Tal como refere CASTELLS, Manuel - A Galáxia da Internet: Reflexões sobre a Internet, os negócios e a sociedade. Rio de Janeiro: Jorge Zahar Editor, 2003, p. 7, Pela primeira vez na história, a mente humana é uma força produtiva direta, não apenas um elemento decisivo do sistema de produção.

28 Ver COMISIÓN TÉCNICA DE LA ESTRATEGIA UNIVERSIDAD - La responsabilidad social de la universidad y el desarrollo sostenible. Secretaría General de Universidades, 2011. Conferência de Reitores das Universidades espanholas, REBIUN.

29 Mediação implícita (processos, nomeadamente o catálogo, que constitui um meio tradicional por excelência de mediação das BU) e Mediação explícita (relação formal com os utilizadores, por ex. através dos Serviços de referência).

30 Ainda que de uma forma passiva ou estática, de levar informação de um lado para o outro. Do latim mediatio, substantivo feminino que significa ato ou efeito de mediar, intermediação.

31 ALMEIDA JÚNIOR, Oswaldo Francisco de - Mediación e información. Ibersid. (2007) 27-35. ISSN 1888-0967, p. 30. 
ticas de ensino superior no domínio da investigação e da aprendizagem, recupera a sua função ancestral educativa.

Contrariamente ao que alguns proclamavam e ainda hoje defendem, não basta ter cidadãos conectados, é preciso ter cidadãos envolvidos no processo de construção do saber.

Neste âmbito, consideramos que a desintermediação anunciada, ingenuamente, pelo paradigma tecnológico - que pretendia reduzir ou eliminar a necessidade, ou a importância, dos Serviços de Informação em geral e das BU em particular - é uma miopia da sociedade da informação.

A necessidade de pôr ordem na desordem, de transformar o valor latente da informação em valor real, abre um campo fértil a estas organizações, às quais se exige que retomem o seu papel original de filtros, de mediadores, de agentes facilitadores do acesso ao conbecimento e do combate à desinformação ${ }^{32}$, recuperando a sua função de refinerías de información donde se busca y recopila un producto en bruto, la información y-lo que es más importante- se transforma en conocimiento 33 .

Ora, aquilo a que pudemos assistir na Sociedade da Informação foi a uma proliferação de dados, em muitos casos inúteis, sem qualquer tipo de significado, em estado bruto. Tal como afirmam TOFFLER, Alvin e TOFFLER, Heidi apesar de las riadas de datos, información y conocimientos que engullimos diariamente, en realidade un percentage cada vez mayor de lo que sabemos es cada vez menos verdade ${ }^{34}$, e é esta necessidade premente de valorizar a informação disponível, de distinguir a boa da má informação, de determinar a qualidade e o valor da informação, que se assume como a missão das BU na Sociedade do Conhecimento.

32 MARQues, Maria Beatriz Pinto de Sá Moscoso - A avaliação dos Outcomes dos Sistemas de Organização e Representação da Informação. In CONGRESSO ISKO ESPANHA E PORTUGAL, $1 .^{\circ}$; CONGRESO ISKO ESPAÑA, 11. ${ }^{\circ}$, Porto, 7 a 9 de Nov. de 2013 - Informação e/ ou Conhecimento: as duas faces de Jano: atas [Em linha]. p. 387-405. [Consult. 2013-11-08]. Disponível na WWW em: <URL: http://www.youblisher.com/p/749221-I-Congresso-ISKOEspanha-e-Portugal-XI-Congreso-ISKO-Espana/, p. 390.

33 ALLEPUZ Ros, Teresa - Gestores y consumidores de información en la economía del conocimiento. In Jornadas Españolas de Documentación, VI,1998 [Em linha]. [Consult. 2004-1118]. Disponível na WWW em: <URL:http://127.0.0.1:4664/cache?event_id=57236\&schema_id= $2 \& q=$ allepuz $\& s=$ glegeXRzcBjHrh9Muz6c514pdqY, p. 3 .

34 TOFFler, Alvin; TOFFLER Heidi - The third wave, p. 168. 
Assim, sobre o novo papel das BU no século XXI, podemos inferir que a sua função de intermediação - entre os dados cada vez mais dispersos e a posse de informação registada e o seu acesso - é enriquecida com a função de educação e de aprendizagem.

Neste novo cenário, a comunicação assume um papel determinante na política das BU e implica o conhecimento dos seres humanos e das suas necessidades, e ainda a capacidade de lhes proporcionar informação útil para o seu desenvolvimento 35 .

As BU assumem o papel de mediadoras para o acesso ao conhecimento através de um processo permanente de comunicação da informação que conservam nas suas coleções, desenvolvendo ações para promover sistematicamente o encontro entre os seus clientes e as suas coleções e avaliando permanentemente o ser bumano e a sua circunstância ${ }^{36}$.

Esta visão da BU pressupõe a necessidade de comunicar, de interagir com o objeto, iniciando assim o processo de conbecer e a sua retroalimentação, possibilitada por uma aprendizagem contínua ${ }^{37}$.

Este novo papel que é atribuído às BU, aumenta substancialmente a visibilidade externa da organização e o reconhecimento interno das suas funções, mas impõe-lhe também novos e complexos desafios, os quais lhe retiram o carácter sacrossanto que sempre a caracterizou e justificou do ponto de vista institucional.

As funções tradicionais das $\mathrm{BU}$, desenvolvidas em torno de princípios fundamentais (como o sejam a igualdade, a neutralidade, a qualidade, etc.), devem agora ser conjugadas com novos modos de funcionamento, fundados em princípios de ação (como a transparência e responsabilidade, simplicidade e acessibilidade, participação e adaptação, confiança

35 RIFKIN, Jeremy - A era do acesso: a revolução da nova economia, p.73-74, afirma mesmo que são as ciências da informação e as ciências da vida - os computadores e os genes - que vão dominar uma grande parte da actividade económica do século XXI.

36 Fórmula proposta pelo filósofo espanhol José Ortega Y Gasset (1914) - Eu sou eu e a minha circunstância - e que ilustra a multiplicidade de pontos de vista em relação à realidade circundante e aos fatores contingenciais que condicionam a vida coletiva e individual.

37 MARQues, Maria Beatriz Pinto de Sá Moscoso - A avaliação dos Outcomes dos Sistemas de Organização e Representação da Informação, p. 397. 
e fiabilidade, etc.), que permitam o estabelecimento de uma ligação direta entre a ação e os resultados dessa ação, consolidando assim as mudanças conjunturais, através da alteração estrutural correspondente ${ }^{38}$.

Isto é, não basta presumir o valor da BU para a comunidade universitária, é necessário evidenciar, demonstrar o seu contributo para o desenvolvimento individual e coletivo, ou seja, as capacidades que os alunos, professores e comunidade em geral adquiriram por aceder à informação, de que forma os seus comportamentos e atitudes se modificaram, que conhecimentos adquiriram $^{39}$, quais as alterações proporcionadas no seu processo de investigação, no seu nível ou qualidade de vida académica e/ou profissional.

Assim, de uma mediação custodial passiva, que surge a partir do séc. XVIII com um caráter patrimonialista, historicista e tecnicista, assente numa abordagem instrumental, prática, normativa e descritiva dos documentos, inaugura-se, a partir do século XXI, ainda que de uma forma lenta e gradual, a mediação pós-custodial ativa e interativa, com um caráter informacional e científico, que pretende compreender e explicar o fenómeno infocomunicacional ${ }^{40}$.

Desta forma evolui-se da preocupação com a organização e representação da informação para a interpretação e descodificação dos mecanismos e obstáculos que se colocam à sua comunicação, nomeadamente quando os emissores são cada vez mais atrativos, as mensagens são em muito maior número, e quando os recetores são cada vez mais exigentes, mais especializados, mais heterogéneos, mais insatisfeitos, exigindo serviços excelentes, preços justos e ofertas inovadoras ${ }^{41}$.

Nesta nova sociedade, designada por digital, e contrariando a divisão binária do universo iluminista - sujeitos cognoscentes activos e objetos

38 MARQUES, Maria Beatriz Pinto de Sá Moscoso - "Utilizadores ou clientes"?, p. 218.

39 MARQUeS, Maria Beatriz Pinto de Sá Moscoso - A avaliação dos Outcomes dos Sistemas de Organização e Representação da Informação, p. 398.

40 Ver SILVA, Armando Malheiro da; RIBEIRO, Fernanda - Paradigmas, serviços e mediações em Ciência da Informação. Recife: Néctar, 2011, p. 180-181.

41 SEYBOLD, Patricia B. - A revolução do cliente. Marketeer. N. ${ }^{\circ} 55$ (2001), p. 78-80. 
de conbecimento passivos $^{42}$ - o sujeito e o objeto são indissociáveis e o mundo passa a ser uma construção do espírito bumano ${ }^{43}$.

Mas esta mudança paradigmática da mediação da BU - do modelo custodial para o pós custodial - não se traduz apenas, como já foi dito, numa mudança de meios - dos analógicos para os digitais.

A Nova Gestão da Coisa Pública implica a passagem de uma lógica de gestão dos meios para uma lógica de avaliação dos resultados, assente em factos e não em suposições, gerando a necessidade de deslocar o enfoque do sistema para os seus usufrutuários, da qualidade das coleções e do desempenho das $\mathrm{BU}$, isto é, da ação dos mediadores para a satisfação das pessoas que constituem a comunidade académica, ou seja, da reação dos mediados em relação ao desempenho do sistema.

Assim, a mudança no modelo de mediação traduz-se numa efetiva mudança de mentalidades no seio dos agentes envolvidos no processo de mediação da informação para acesso ao conhecimento.

De facto, na Era Digital, a mediação das BU implica um reposicionamento da sua gestão estratégica do interior da organização para o seu exterior, de uma visão centrada no sistema de informação para uma visão centrada no produtor e consumidor da informação, e tem como pressuposto uma mudança terminológica inerente à análise da evolução social subjacente à passagem do conceito de UTILIZADOR - o proprietário da informação -, ao conceito de CLIENTE ${ }^{44}$ - o que acede à informação

42 RIFKIN, Jeremy - A era do acesso: a revolução da nova economia, p.231.

43 Como afirma RIFKIN, Jeremy - A era do acesso: a revolução da nova economia, p.234, já não se trata de um mundo de objectividade mas de contingência, já não assenta em verdades mas em opções e cenários.

44 A distinção terminológica, que surge na literatura anglo-saxónica, justifica-se pelo objetivo de apresentar a noção de serviço como integrado na construção de um sistema global, em que o leitor é considerado não só como um usufrutuário, mas como parte integrante dele. O que está em causa na mudança terminológica proposta - de utilizador, para cliente -, não é de todo uma rutura com uma história secular, e muito menos uma alteração profunda da matriz fundadora dos Serviços de Informação de Arquivo e de Biblioteca Recolber, Conservar e Difundir a memória da bumanidade -, mas sim um enquadramento bistórico e uma adaptação da sua missão, e das suas funções, aos novos contextos sociais, de forma a permitir o estabelecimento de prioridades para o novo século, assentes numa lógica de melhoria contínua e qualidade total do seu funcionamento. MARQUES, Maria Beatriz Pinto de Sá Moscoso - Utilizadores ou clientes?, p. 218-219. O ‘cliente' é o indivíduo (ou organização) colocado no centro dos processos de transferência de informação que a BU 
- e, ainda que muito recentemente, ao designado PROSUMIDOR ${ }^{45}$ - o que produz e consome a informação produzida, em prol do bem-estar individual e coletivo ${ }^{46}$.

$\mathrm{Na}$ Sociedade do Conhecimento, evolui-se da visão vanguardista da última década do século passado, centrada na criação de mecanismos e processos de desmaterialização e acesso universal à informação, para uma visão inovadora, que focaliza toda a sua atenção no processamento e uso individual da maior riqueza das nações - a informação processada em benefício da estabilidade e do desenvolvimento bumano ${ }^{47}$.

Assim, a vitalidade da informação não é conferida pela passagem de um cemitério físico, para um cemitério digital. Essa vitalidade não é atingida pela simples disponibilização de informação na Web, ainda que em constante crescimento. Para que a informação acumulada pelo ser humano seja útil, é necessário que ela alimente a capacidade cognitiva, exclusiva do ser humano, de gerar conhecimento, de ser criativo e inovador.

Neste contexto, quem determina o valor económico e social das BU é a comunidade académica - Estudantes, Professores, Investigadores, Pessoal e Comunidade em geral, os clientes reais e/ou potenciais, físicos ou virtuais - e não as suas tutelas ${ }^{48}$. Daí a necessidade de desenvolver mecanismos de atração, captação e sobretudo de fidelização dos chamados Stakeholders em sentido lato, tal como foram definidos por Peter Brophy

assegura, transformado em razão primeira da sua existência e em fulcro do conjunto de todas as atividades desenvolvidas.

45 A sociedade de consumo passava a ser constituída pelos Prosumidores, palavra inventada por TOFFLER, Alvin - Op. cit. para designar aqueles que, a título individual ou coletivo, PROduzem e conSOMEM os seus próprios outputs. Sobre o conceito de prosumidor, veja-se a obra de TOFFler, Alvin; TOFFlER, Heidi - Op. cit., p. 217-286.

46 Os chamados seres humanos proteiformes que se metamorfosearam de trabalhador produtivo em consumidor informado e deste último em protagonista de representações criativas. In RIFKIN, Jeremy - A era do acesso: a revolução da nova economia, p. 258.

47 MARQues, Maria Beatriz Pinto de Sá Moscoso - A avaliação dos Outcomes dos Sistemas de Organização e Representação da Informação, p. 394.

48 De acordo com esta nova visão, a qualidade total das organizações passa a ser dirigida pelo cliente e não, como até agora, pelo menos nas ONL, imposta pelas organizações, de acordo com as análises feitas a partir das torres de marfim das empresas. In MARQUES, Maria Beatriz Pinto de Sá Moscoso - Utilizadores ou clientes?, p. 214. 
em $1995^{49}$, ou seja, as pessoas, grupos ou organizações que, direta ou indiretamente, se relacionam com a organização, que têm algum interesse nela, que a afetam ou por ela são afetados ${ }^{50}$.

\section{Conclusão}

Como súmula da mensagem que pretendemos comunicar, consideramos que a discussão epistemológica sobre o ser humano e as suas relações tradicionais de reciprocidade, baseadas na afeição, no amor e na dedicação ${ }^{51}$, deverá ser a pedra de toque da Sociedade do Conhecimento, indo muito além do growth of userism in recent Web thinking can be understood partly in relation to the prevailing neo-liberalistic view of society. When buman beings are reduced to customers, consumers or users, society can be reduced to a market $^{52}$.

Para ultrapassar o reducionismo da Sociedade da Informação, que acentuou o abismo entre o potencial tecnológico e a sabedoria humana, é necessário reafirmar o valor da relação entre o ser humano espiritual e a informação disponível, entre o uso e os usuários. É do outcome 53 desta relação que resulta o progresso da humanidade.

Contrariamente a todas as outras substâncias, onde se verifica uma relação desproporcional entre o valor de uso e o valor de troca - the

49 Ver também a definição de público dada por KOTLER, Philip - Marketing para organizações que não visam o lucro. São Paulo: Atlas, 1994. ISBN 85-224-0397-X, p. 33.

50 Consideram-se stakeholders dos Serviços públicos, para além dos chamados clientes finais, todos os clientes internos e externos da cadeia de produção e, no caso dos serviços públicos, a totalidade dos cidadãos, com expectativas e percepções muito diferenciadas. NOGUEIRA, S. G. (2008). Qualidade e satisfação em serviços de saúde: uma abordagem da avaliação do desempenho [Em linha]. Lisboa: [s.n.]. [Consult. 2011-05-16]. Disponível em WWW: http://repositorio-iul.iscte.pt/bitstream/10071/1374/1/Qualidade $\% 20 \mathrm{e} \% 20$ Satisfa\%c3\%a7\%c3\%a3o\%20em\%20Servi\%c3\%a7os\%20de\%20sa\%c3\%bade.pdf. Tese de Mestrado em Sociologia apresentada ao ISCTE, p. 13.

51 RIFKIN, Jeremy - A era do acesso: a revolução da nova economia, 141

52 NORUZI, Alireza - Application of Ranganathan's Laws to the Web. Webology. [Online]. Vol. 1, $\mathrm{n}^{\circ} 2$, (2004). [Consult. 2013-03-20]. Available in www:URL:http://www.webology. ir/2004/v1n2/a8.html.

53 Do impacto que a informação tem nos seus utilizadores e na sociedade. 
things which have the greatest value in use have frequently little or no value in exchange; and, on the contrary, those which have the greatest value in exchange have frequently little or no value in use $e^{54}$, o valor do conhecimento aumenta em função do seu uso - cuanto más conocimiento utilizamos, más del mismo creamos $^{55}$.

Assim, na continuidade do pensamento de Tom Peters e Bob Water$\operatorname{man}^{56}$, considerar as pessoas, e não as máquinas, o dinheiro ou mesmo os cérebros, como um recurso natural, talvez seja o sucesso de tudo, e constitua a tão almejada vantagem competitiva das BU na Era Digital.

Em congruência, uma BU será cara ou barata, boa ou má, rica ou pobre quando comparada com outras organizações concorrentes em função da excelência do seu desempenho e essa só pode ser reconhecida olhando para a organização através dos olhos dos utilizadores, perguntando-lhes...

- Qual é a imagem da Biblioteca da Universidade na estrutura académica?

- Qual é o seu contributo para o progresso do ensino, da aprendizagem e da investigação?

- Qual é o contributo da Biblioteca da Universidade para reforçar a autonomia dos estudantes na aprendizagem?

- Qual é a qualidade e a quantidade da informação necessária para atingir a criatividade, a inovação e o conhecimento?

- Qual é o contributo da Biblioteca Universitária para a aprendizagem dos estudantes ao longo da vida?

- Qual é o grau de abertura sistémica da Biblioteca da Universidade ao cidadão, às empresas e às organizações?

\footnotetext{
54 Adam Smith exemplifica esta relação através da água, dizendo que nothing is more useful than water; but it will purchase scarce any thing; scarce any thing can be had in exchange for it. A diamond, on the contrary, has scarce any value in use; but a very great quantity of other goods may frequently be had in exchange for it. In SMITH, Adam - Op. cit., Primeiro Volume, Livro Primeiro, Capítulo IV.

55 TOFFLER, Alvin; TOFFLER Heidi - The third wave, p. 160.

56 PETERS, Thomas J.; WATERMAN JR., Robert H. - In search of excellence $=\mathrm{Na}$ senda da excelência: o exemplo das empresas norte-americanas mais bem geridas. $2 .^{a}$ ed. Lisboa: Publicações Dom Quixote, 1987. ISBN 972-20-0035-7, p. 58.
} 
- Quais são as necessidades de informação dos clientes da Biblioteca da Universidade?

- Quais são as suas expectativas?

- Qual é o seu grau de satisfação?

- Quais são as estratégias e os canais de comunicação com os clientes da Biblioteca da Universidade?

As respostas que obtivermos a estas perguntas, ajudar-nos-ão a determinar o valor das BU na Sociedade da Informação e do Conhecimento.

\section{Referências bibliográficas}

ALLEPUZ ROS, Teresa - Gestores y consumidores de información en la economía del conocimiento. [Em linha]. In Jornadas Españolas de Documentación, VI, 1998. [Acedido a 28 de jan. de 2014]. Disponível na WWW em: <http://127.0.0.1:4664/ cache?event_id=57236\&schema_id=2\&q=allepuz\&s=glegeXRzcBjHrh9Muz6 c514pdqY>.

ALMEIDA JÚNIOR, Oswaldo Francisco de - Mediación e información. Ibersid. (2007) 27-35. ISSN 1888-0967.

CAPURRO, R. - Epistemología y ciencia de la información. Acimed: revista cubana de los profesionales de la información y la comunicación en salud. 21:2 (2010), 248-265.

CASTELLS, Manuel - A Galáxia da Internet: reflexões sobre a Internet, os negócios e a sociedade. Rio de Janeiro: Jorge Zahar Editor, 2003.

CASTELls, Manuel - A sociedade em rede - a era da informação: economia, sociedade e cultura. Vol. 1. São Paulo: Paz e Terra, 1999.

COMISIÓN TÉCNICA DE LA ESTRATEGIA UNIVERSIDAD - La responsabilidad social de la universidad y el desarrollo sostenible. Secretaría General de Universidades, 2011. Conferência de Reitores das Universidades espanholas, REBIUN.

DAVAllon, Jean - A mediação: a comunicação em processo? Prisma.com. 1 (2007), 3-36.

DRUCKER, Peter F. - Post-Capitalist Society. New York: Harper Collins, 1993. 
DUVOLD, Ellen-Merete - The meaning of the public library in people's everyday life: some preliminary results from a qualitative study. In JOHANNSEN, Carl Gustav; KAJBERG, Leif, ed. - New frontiers in public library research. Maryland: Scarecrow Press, 2005. ISBN 0-8108-5039-7.

THE ECONOMICS OF INFORMATION. In International Encyclopedia of Information and Library Science. London; New York: Routledge, 1997. ISBN 0-415-09860-2.

GALVÃO, Maria Cristiane Barbosa - Construção de conceitos no campo da Ciência da Informação. Ciência da Informação. 27:1 (1998).

KOTLER, Philip - Marketing para organizações que não visam o lucro. São Paulo: Atlas, 1994. ISBN 85-224-0397-X.

LANCASTER, Frederick Wilfrid - If you want to evaluate your library. 2nd ed. London: Library Association Publishing, 1993. ISBN 1-85604-083-6.

LANCASTER, Frederick Wilfrid - The measurement and evaluation of library services. Washington: Information Resources, 1977. ISBN 087815017X.

MARQUES, Maria Beatriz Pinto de Sá Moscoso - "A avaliação dos outcomes dos sistemas de organização e representação da informação". In CONGRESSO ISKO ESPANHA E PORTUGAL, 1..$^{\circ}$ CONGRESO ISKO ESPAÑA, 11 ${ }^{\circ}$, Porto, 7 a 9 de Nov. de 2013 Informação e/ou Conbecimento: as duas faces de Jano: atas [Em linha]. p. 387-405. [Acedido a 8 de nov. de 2013]. Disponível na WWW em: <http://www.youblisher. $\mathrm{com} / \mathrm{p} / 749221-I-C o n g r e s s o-I S K O-E s p a n h a-e-P o r t u g a l-X I-C o n g r e s o-I S K O-E s p a n a>$.

MARQueS, Maria Beatriz Pinto de Sá Moscoso - Utilizadores ou clientes? inovação na visão dos serviços de informação no século XXI. In SEMINÁRIOS DE SABERES ARQUIVÍSTICOS (SESA) - Reflexões e diálogos para formação do arquivista. Curitiba: Appris, 2013. Vol.1, p. 181-204. ISBN 978-85-8192-225-6.

MARTÍN BARBERO, Jesús - Dos meios às mediações: comunicação, cultura e hegemonia. 6. ${ }^{a}$ ed. Rio de Janeiro: UFRJ, 2009.

MATOS, Florinda; LOPES, Albino - Gestão do capital intelectual: a nova vantagem competitiva das organizações. [Em linha]. Comportamento Organizacional e Gestão . 14:2 (2008), 234. [Acedido a 28 de abril de 2013]. Disponível na WWW em: <http://wWw.scielo.oces.mctes.pt/pdf/cog/v14n2/v14n2a07.pdf>.

McGARRY, K. J. - Da documentação à informação: um contexto em evolução. Lisboa: Editorial Presença, 1984.

NogueIRA, S. G. (2008). Qualidade e satisfação em serviços de saúde: uma abordagem da avaliação do desempenho [Em linha]. Lisboa: [s.n.]. [Acedido a 16 
de maio de 2011]. Disponível na WWW em: <http://arepositorio-iul.iscte.pt/ bitstream/10071/1374/1/Qualidade\%20e\%20Satisfa\%c3\%a7\%c3\%a3o\%20em\%20 Servi\%c3\%a7os\%20de\%20sa\%c3\%bade.pdf>. Tese de Mestrado em Sociologia apresentada ao ISCTE.

NORUZI, Alireza - Application of Ranganathan's Laws to the Web. [Em linha]. Webology. 1:2 (2004). [Acedido a 20 de mar. de 2013]. Disponível na WWW em: <http://www.webology.ir/2004/v1n2/a8.html>.

PETERS, Thomas J.; WATERMAN JR., Robert H. - In search of excellence $=\mathrm{Na}$ senda da excelência: o exemplo das empresas norte-americanas mais bem geridas. 2. ${ }^{\text {a }}$ ed. Lisboa: Publicações Dom Quixote, 1987. ISBN 972-20-0035-7.

Principes directeurs pour l'évaluation des systèmes et services d' information. Paris: Unesco, 1978. 180 p. (Unesco; PGI-78/WS/18).

RIFKIN, Jeremy - A era do acesso: a revolução da nova economia. Lisboa: Editorial Presença, 2001. ISBN 972-23-2741-0.

SEYBOLD, Patricia B. - "A revolução do cliente". Marketeer. N. 55 (2001), p. 78-80.

SILVA, Armando Malheiro da - Mediações e mediadores em Ciência da Informação. Prisma.com. 9 (2010).

SILVA, Armando Malheiro da; RIBEIRO, Fernanda - Paradigmas, serviços e mediações em Ciência da Informação. Recife: Néctar, 2011, p. 180-181.

TOFFLER, Alvin - The third wave. New York: Bantan Books, 1981. ISBN 0-553-22635-5.

TOFFLER, Alvin; TOFFLER Heidi - La revolución de la riqueza. Barcelona: Debate, 2006. ISBN 84-8306-674-2. 
José Augusto Cardoso Bernardes é Professor da Faculdade de Letras da Universidade de Coimbra e Diretor da Biblioteca Geral da Universidade

Ana Maria Eva Miguéis é coordenadora do Serviço Integrado das Bibliotecas da Universidade de Coimbra

Carla Ferreira é bibliotecária nos Serviços de Biblioteca e Documentação da Faculdade de Letras da Universidade de Coimbra. 


\section{Série Documentos}

Imprensa da Universidade de Coimbra

Coimbra University Press

2015

C •

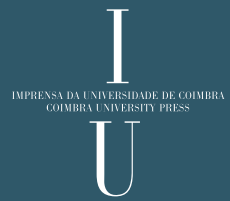

